\title{
Design and Modification the Existing Bhoramdev Seed Drill
}

\author{
Kanhaiya Lal $^{1 *}$, D. Padhee ${ }^{2}$ and Shambhu Singh ${ }^{1}$ \\ ${ }^{1}$ SV College of Agricultural Engineering and Technology and Research Station, \\ FAE, IGKV, Raipur (C.G), India \\ ${ }^{2}$ BRSM College of Agricultural Engineering and Technology and Research Station, \\ Mungeli, FAE, IGKV, Raipur (C.G), India \\ *Corresponding author
}

\section{A B S T R A C T}

\begin{tabular}{|l|}
\hline Ke y w o r d s \\
Animal drawn, Seed \\
drill, Design, Auto \\
CAD.
\end{tabular}

Bhoramdev seed drill is the most commonly used farm tool in Chhattisgarh. Never the less, using this plough as farm tool is labour intensive, time taking, making shallow depth and narrow cutting width. Thus, this research is initiated to come up with a solution to the aforementioned problems. Therefore, the objectives of this research were to model the basic components of animal drawn modified bhoramdev seed drill, to fabricate and test the prototype. Alternative options were considered for conceptual design among these, without seat to operator, handles and beam attachment design alternative is selected using meritdemerit analysis. In addition, after the detail design, the prototype is fabricated in at BRSM CAET \& RESEARCH STATION MUNGELI, IGKV Raipur (C.G.) Workshop using locally available. The newly designed prototype reduces time spent and reducing of human drudgery while ploughing. The drawing of the conceived seed drill was prepared using autocad software. To achieve these a prototype consisting of seed hopper, orifice and agitator, frame, furrow opener and beam for hitching arrangement was developed. The construction of the implement was the main study.

\section{Introduction}

Indian agriculture is suffering from huge power shortage. It has a total of 37.86 million hp available on our farms against the minimum requirement of 112 million hp. 70 per cent of the power available to our farms is supplied by animals and, further, 70 per cent of the farm holders are small and marginal in India and almost all of them use animal as a source of power. Therefore, efforts have to be made for the development of improved animal drawn implements.

In India crops are usually sown by broadcasting, dibbling, seeding behind the Plough cind line sowing using furrowing implements and manual dropping of Seeds. Fertilizer is either broadcasted before sowing the crop or top-dressed after the crop has been 
sown. Broadcast seeds are prone to remain dry resulting in their Failure to germinate. Moreover, seeds may be wasted due to birds, rodents and Oilier pests. In case of heavy rainfall, seeds may also be lost due to run off. Also, Subsequent intercultural operations may not be performed under very wet conditions even with improved weeding tools. Thus labour saved by broadcasting fc-ds is offset by subsequent operations and yield lost due to poor crop establishment. Manual dibbling is practiced for crops, like groundnut, sorghum, Soyabean, cotton, etc., which require wide-row spacing and low density plant populations. Manual dibbling is a time-consuming operation requiring 200250 man-hours per hectare (RNAM, 1991).

Among other methods of crop Establishment, line sowing is the most efficient means to sow the crops and the most ideal for crop management. Any method should ensure a better condition for Seed emergence. Seedling emergence is a straight forward process. Good crop establishment depends on the quality of seeds sown as well as good seed bed and weather conditions. Under field conditions, factors which affect seed emergence include seed and soil characteristics as well as machines used for sowing or planting. Different types of seed drills, seed-cum fertilizer drills and planters have been developed to suit the various sources of power available in farmer's fields. Many experiments indicate that optimum plant population achieved by seed drill significantly contributes to high yields. But most of the sowing equipments do not reach the farmers in General, and among dry land farmers in particular fine to poverty, ignorance and poor extension efforts.

Bhoramdev seed drill is a animal drawn seed drill. It is a low cost line-sowing device in which seed metering is done manually by the operator by dropping the seeds in the funnel provided for the purpose. Hence the skill of the operator determines the seed rate applied. It is a four row sowing device. The drill consists a frame of mild steel box section, furrow openers cum shanks, funnels with two spouts for feeding seed, hoses for connecting funnels with pipes mounted on "furrow openers, hitch assembly and handle. The distance between the rows can be adjusted by moving the furrow openers cum shanks. The furrow opener is of angle iron, which is pointed at the end. Since the drill does not have a separate hopper, seeds have to be carried separately in a bag slung on the shoulder or the back of the operator. It is used for line sowing of cereal and other crops. Specifications of existing seed drill are show (Table 1).The CAD Software was used for the design of components of seed drill as well as their assembly.

The solid modeling for all the components, sub-assemblies and design document were prepared before fabricating machine in the workshop. The drawings were prepared through CAD. The seed drill was designed, fabricated and tested in the laboratory as well as in the field to assess the functional performance at BRSM Collage of Agril, Engineering and technology research station Mungeli, IGKV Raipur during the year 20142015. The machine consisted of frame, power transmission unit, seed metering device, seed and fertilizer box, furrow openers, hitch attachment and beam. The construction of machine was made study and lightweight matching to the pulling capacity of small/medium pair of bullocks.

\section{Problem detection in seed drill}

The existing seed drill are observed and studied properly to detect the problems faced by farmer. 


\section{New technology}

The research work in this domain was studied and new methods were developed to achieve desired goal.

\section{Safety}

To make it easy to operate and safety of the operator.

\section{Construction and working of modified bhoramdev bullock drawn seed drill}

The main components of modified bhoramdev seed drill are as below-

\section{Main frame}

The whole assembly was mounted on a tubular frame constructed by angle iron frame. A rectangular frame was developed with suitable dimensions to be mounted on this frame. Dimension:800×1330 mm.

\section{Design of Hopper}

Hopper is made of ms sheet. Its dimension is $300 \mathrm{~mm} \times 200 \mathrm{~mm} \times 150 \mathrm{~mm}$. It consists of: agitator , shaft, spring, lever \& wire and bearing. Capacity: $5 \mathrm{~kg}$

\section{Design of shaft and bearing}

Shaft is made of MS rod and its both side attach with bearing at both end of the box. The shaft diameter and length is $11 \mathrm{~mm}$ and $400 \mathrm{~mm}$ respectively. It's made of mild steel. A Shaft is a rotating element, usually circular in cross section; line shaft is used to transmit power from direct agitators.

\section{Design of furrow opener}

These are the parts which open up furrows in the soil for placing the seeds.It has furrow opener cum shank. No. of furrow opener is four and all furrow opener connected to hose pipe with boot. Furrow opener is made of angle iron.

\section{Seed tube}

The seed tubes made from transparent PVC pipe are fitted, so as to connect the seed hopper outlet to furrow opener. The seed tube carried the cereal kernels discharged from the seed hopper to the furrow openers. It was easy to fix and remove the seed tubes as it was made of flexible PVC pipe. Moreover, its being transparent and allowed the observation of the flow of seeds. The inside diameter of the seed tube is $22 \mathrm{~mm}$ and its thickness and length are $5 \mathrm{~mm}$ and $450 \mathrm{~mm}$ respectively.

\section{Hitching bar}

The hitching bar was required to connect the frame of the seed drill to the wooden beam. It consisted of two limbs, each of which was made up of $35 \times 35 \times 5 \mathrm{~mm}$ M.S. angle welded to form a hollow cross section. The total length of each limb was $780 \mathrm{~mm}$ and was made up of three pieces.

They were welded in such a way that, when both the limbs were fitted to the beam the gap between two limbs at the front end was 50 $\mathrm{mm}$, and $250 \mathrm{~mm}$ on rear end. The wooden beam, in turn, was connected to the yoke of the bullocks.

\section{Design of lever with wire conveyor system}

Horizontal conveying length and conveying lift of agitator, characteristics of material to be conveyed and capacity requirement.

\section{Cover sheet}

Housing covers the seed box. Whatever sowing operation is done it takes place within the housing. It protects the worker from any injury during operation. 


\section{Procedure}

For operating the seed drill in the field, one end of a wooden beam was attached to the hitching bar and the other end was connected to a yoke with the help of rope. The hoppers were filled with, good quality of seeds. The whole unit was taken to the field, having well prepared seed-bed. The seed drill was operated (pulled) by a pair of bullocks. Fig. 9 shows the seed drill under operation. During operation, the hand lever operated by operator, there by the feed shaft with agitator was also semi rotated through shaft and bearing. The feed shaft bearing. Hence, the feed shaft also semi rotated like that pendulum with the same speed. As the agitator mounted on the feed shaft rotated, they discharged the cereal from the hoppers to the seed tube. The hopper feed hole were also forward and backward along with the feed shaft. Two to three cereals got filled in the hopper feed hole. The kernels (seeds) were discharged to the seed box. The seeds so discharged, were carried to the furrow openers through transparent PVC tubes and placed in the furrows, opened by furrow openers. The notch at the rear end of the furrow opener ensured a proper covering of seeds with the soil.

Table.1 Specifications of bharamdev seed drill

\begin{tabular}{|l|l|}
\hline Specifications & \multicolumn{2}{|l|}{} \\
\hline Overall dimensions $(\mathbf{m m})$ & \\
\hline Length $\times$ Width $\times$ Height & $\mathbf{7 4 0} \times \mathbf{5 2 5} \times 1030$ \\
\hline Weight $(\mathbf{k g})$ & $\mathbf{2 0}$ \\
\hline Capacity (ha/day) & $\mathbf{0 . 8}-1.0$ \\
\hline Power requirement & a pair of bullocks \\
\hline
\end{tabular}

Table.2 Specification of the modified bhoramdev seed drill is as follow

\begin{tabular}{|l|c|}
\hline Type & Animal drawn 4 row with marker adjustable \\
\hline Overall length(mm) & 1330 \\
\hline Overall width(mm) & 580 \\
\hline Overall height(mm) & 1040 \\
\hline Total weight & 25 kg with yoke and beam \\
\hline Labour requirement & One man \\
\hline Power requirement & Pair of bullocks \\
\hline Effective Field Capacity(ha/h) & 0.135 \\
\hline Field efficiency $(\%)$ & 70 \\
\hline Seed rate of sowing $(\mathrm{kg} / \mathrm{ha})$ & 40.8 \\
\hline Farrow opener types & furrow openers cum shanks \\
\hline Metering mechanism & agitator orifice type \\
\hline
\end{tabular}




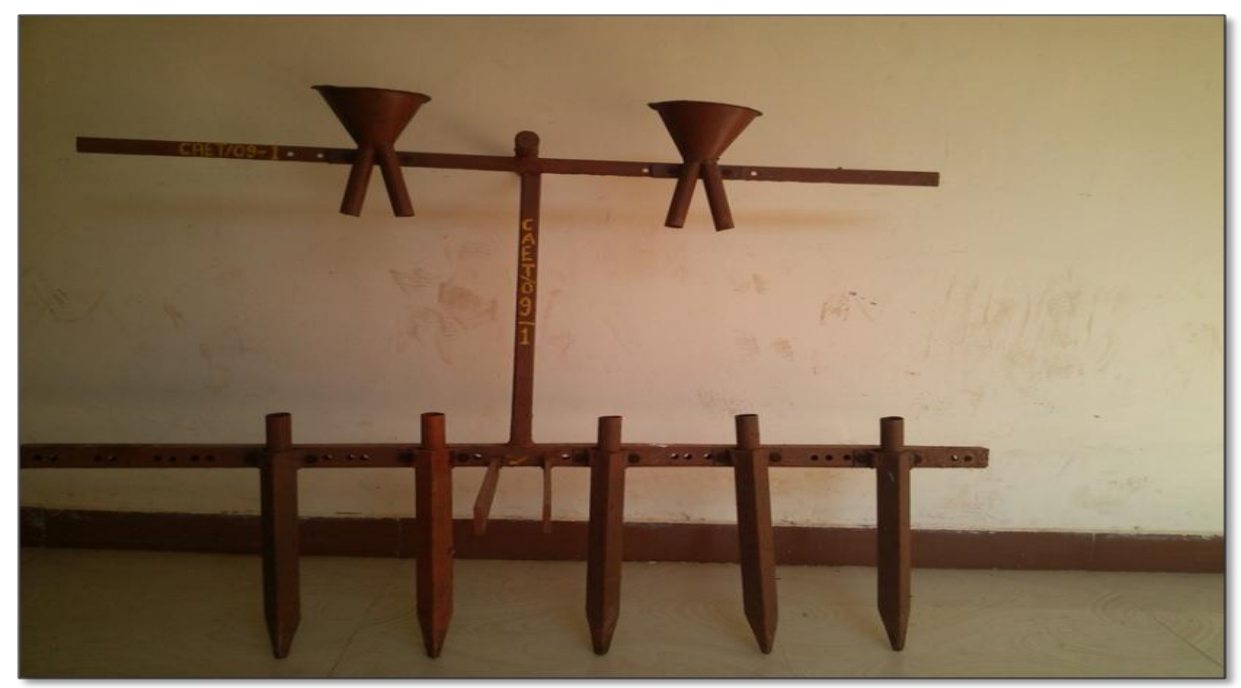

Fig.1 Existing bhoramdev seed drill

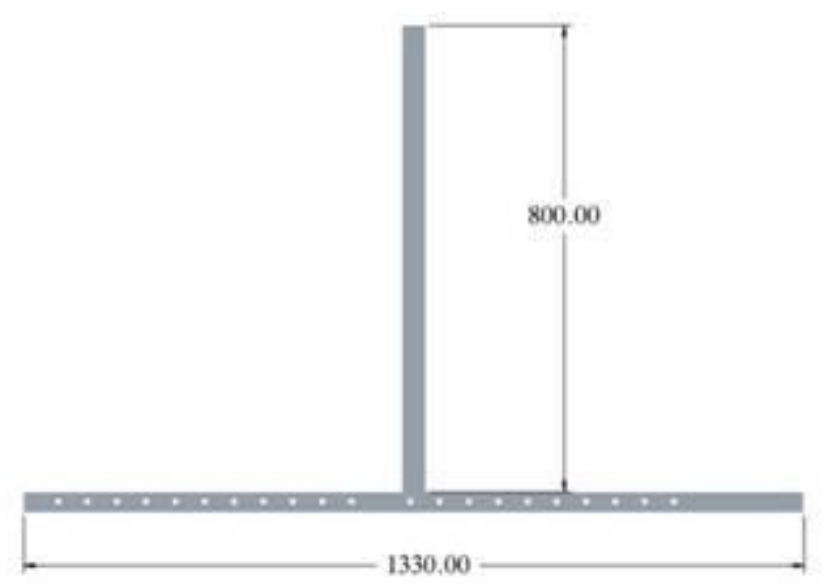

Fig.2 AutoCAD design of frame with dimensions

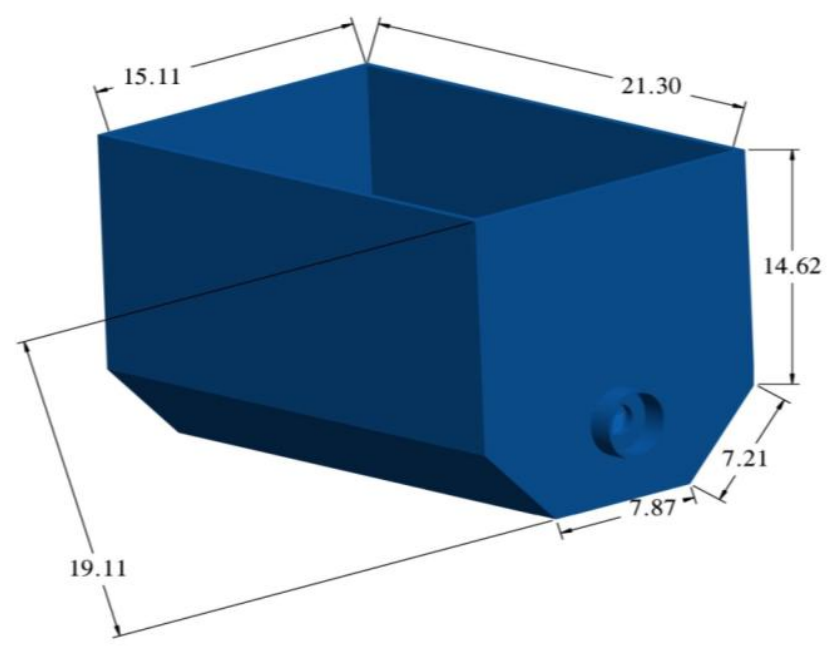

Fig.3 Design of hopper 

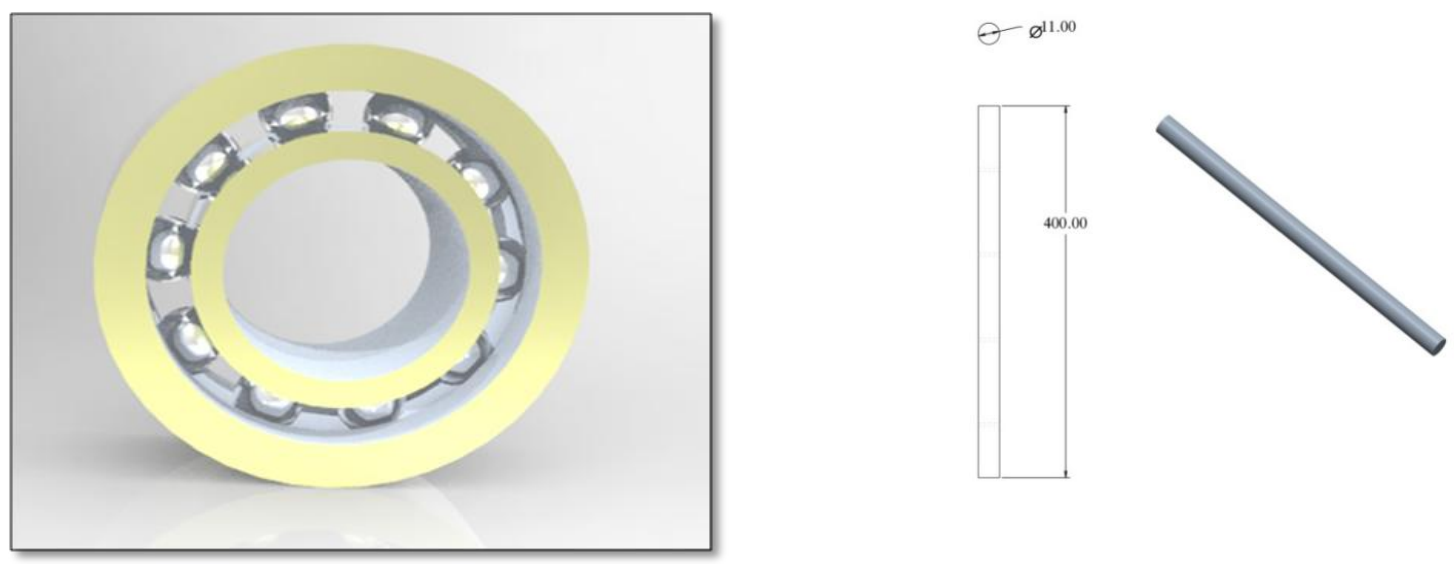

Fig.4 Design of shaft and bearing

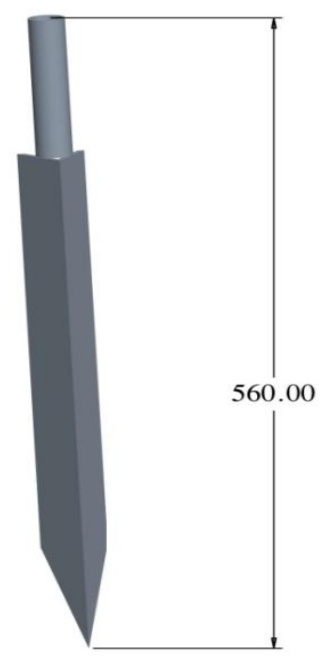

Fig.5 Design of furrow opener cum shank
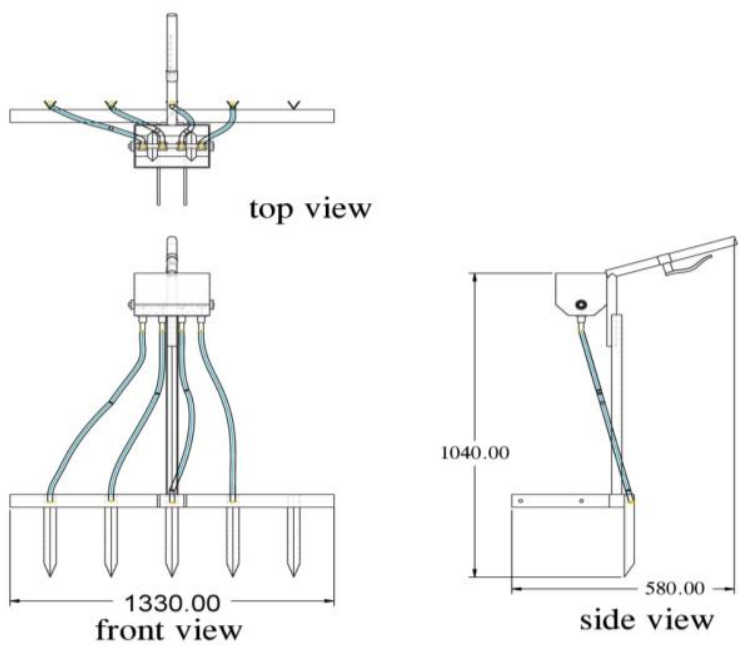

Fig.6 Assembly: - Isometric view of the modification of bhoramdev seed drill 


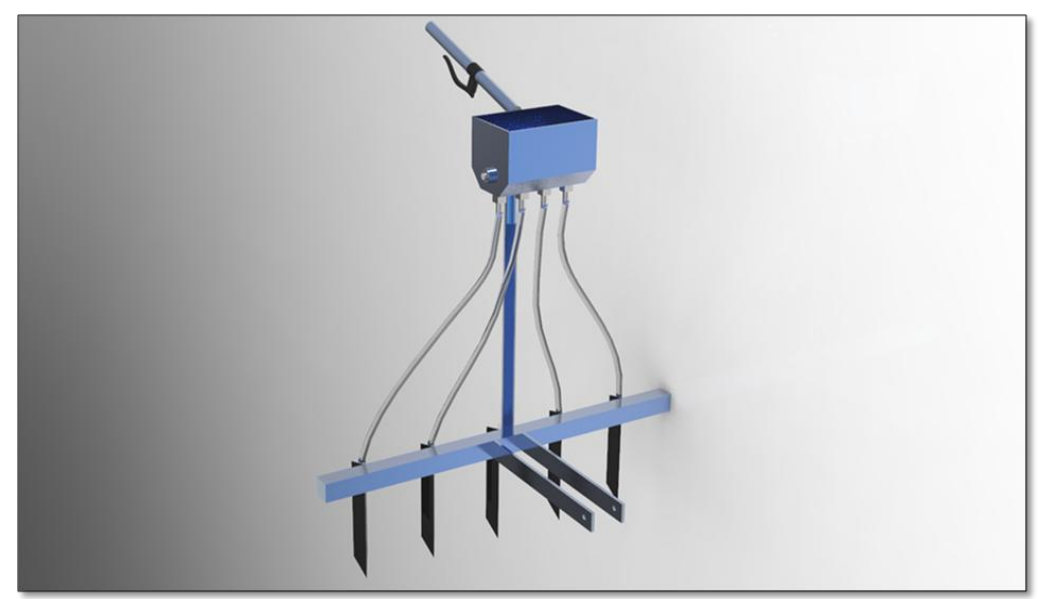

Fig.7 3D view

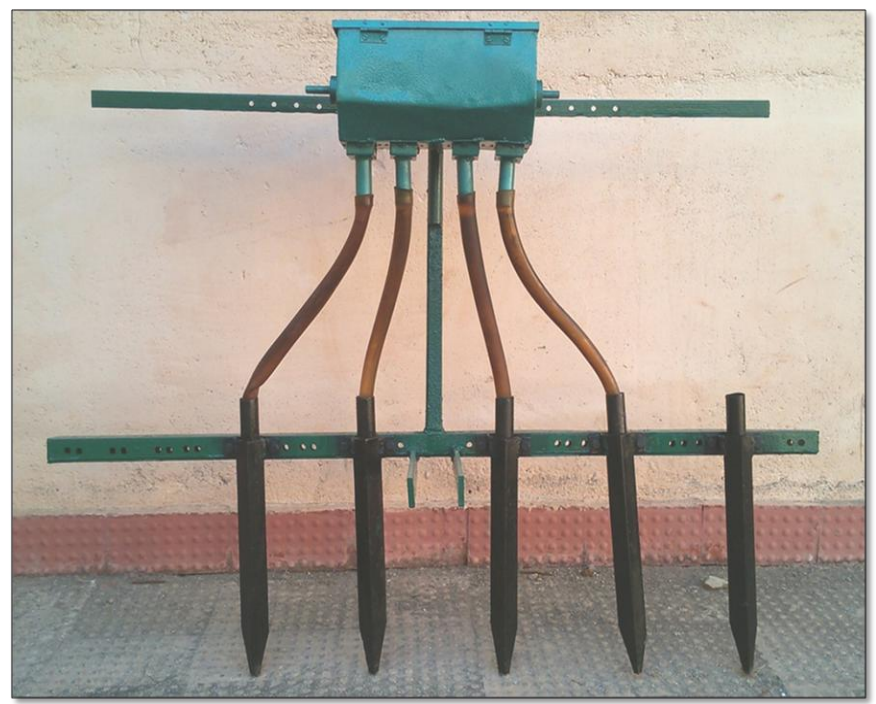

Fig.8 Modified bhoramdev seed drill after fabrication

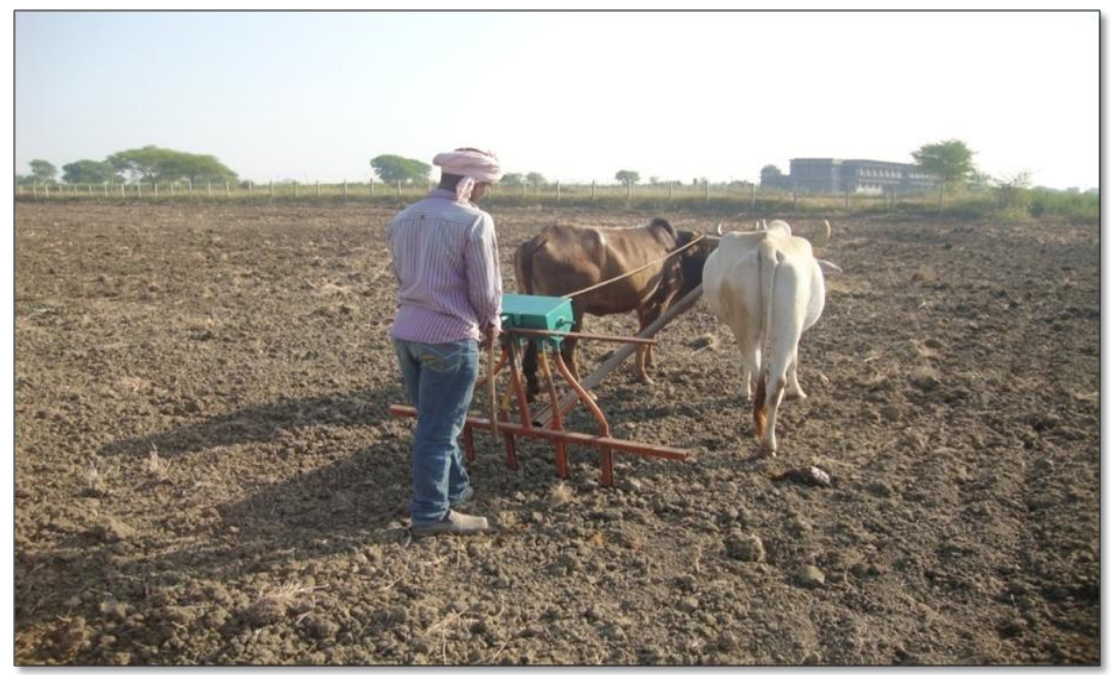

Fig.9 Modified Bhoramdev animal drawn seed drill 


\section{Advantages of modified seed drill}

Following are the advantages of animal drawn modified seed drill are:

It was made of durable and cheap material affordable for the small scale peasant farmers.

Lesser maintenance cost.

The seed can be placed at required depth. The seed germination can be improved. Requirement of labour also decreased. It consume less time for sowing.

Modified animal drawn bhoramdev seed drill sowing implement has remarkable influence in agriculture. By using seed sowing implement we can save more time required for seeding process. And also it reduces lot of labourer cost. It is very helpful for small scale farmers.

\section{References}

Awadhwal, N.K., T. Takenaga and R.K. Bansal. Development of Improved agricultural Implements at ICRISAT. AMA. 18(3) .pp: 21-25. 1987.

Aziz Ozmerzi. Seed distribution performance of the furrow openers used on drill machines. AMA 17(2). pp-.32-34. 1980.

Bahl, V. P, D.N. Sharma and M.L.Jain.
Design of single row bullock-drawn seed-cum fertilizer drill. ISAE. New Delhi, paper No.80-0100. 1980.

Guadie,A.F., Degu Y.M.and GuadieY.F. Design, Fabrication and Testing of Animal Drawn Multiple Mouldboard Plough. World J. Agric. Sci., 14 (5): 151-162, 2018

Kyada, A. R, Patel, D. B. Design and Development of Manually Operated Seed Planter Machine. 5 th International \& 26th All India Manufacturing Technology, Design and Research Conference, IIT Guwahati, Assam, India. pp.590599.(2014)

Ojha, T.P. and Michael, A.M., Principles of Agricultural Engineering, Jain Brothers, New Delhi, 1: $472-473$ (2010).

Ramesh, D. and Girishkumar, H.P. Agriculture Seed Sowing Equipments: A Review. International Journal of Science, Engineering and Technology Research (IJSETR), 3(7):1987-1992. July 2014

Rushabh A. Chilatre et al., Modified Bullock Cart Int J S Res Mech \& Mtrls Engg. 2(2) : 01-07 (2018)

Sharma, D. N. and Mukesh, S., Farm Machinery Design: principles and problems, Jain Brothers, New Delhi (2008).

\section{How to cite this article:}

Kanhaiya Lal, D. Padhee and Shambhu Singh. 2020. Design and Modification the Existing Bhoramdev Seed Drill. Int.J.Curr.Microbiol.App.Sci. 9(05): 1082-1089.

doi: https://doi.org/10.20546/ijcmas.2020.905.119 